\title{
MONITORING OF TURNAROUND TIME IN DIAGNOSING CORONAVIRUS DISEASE-19 SAMPLES: NEED OF THE HOUR
}

\author{
ANUPRIYA A, DIEGO EDWIN, LALITHAMBIGAI J, PRABHUSARAN N* \\ Department of Microbiology, Trichy SRM Medical College Hospital and Research Centre (Affiliated to The Tamil Nadu Dr. M.G.R. Medical \\ University, Chennai), Tiruchirapalli, Tamil Nadu, India. Email: leptoprabhu@gmail.com
}

Received: 25 May 2021, Revised and Accepted: 22 July 2021

\begin{abstract}
Objective: To evaluate laboratory turnaround time (TAT) and to find out the reasons for delay in TAT in diagnosing coronavirus disease (COVID) samples.

Methods: This cross-sectional, descriptive, and observational study was conducted from August 2020 to March 2021 in a Tertiary care teaching hospital. TAT was calculated from sample reception to report dispatch.

Results: Of the 4500 samples analyzed in Molecular Laboratory for the purpose of COVID diagnosis, 890 (19.7\%) had delayed TAT. The average TAT of samples in Emergency and Intensive care units (ICU) is $3 \mathrm{~h}$; and it is $3 \mathrm{~h}$ and $30 \mathrm{~min}$ in inpatient and outpatient (OP) services. The average prolonged TAT is $3 \mathrm{~h}$ and $30 \mathrm{~min}$ and $4 \mathrm{~h} 10 \mathrm{~min}$ in Emergency care, ICU services, and inpatient and OP services respectively. The reasons for prolonged TAT includes payment for tests in the cash unit, repetition of test, specimen related, reagent related, machine breakdown, and software related.
\end{abstract}

Conclusion: The TAT demonstrates the need for improvement in the pre- and post-analytical period.

Keywords: Molecular biology lab, Coronavirus disease-19, Turnaround time.

(C) 2021 The Authors. Published by Innovare Academic Sciences Pvt Ltd. This is an open access article under the CC BY license (http://creativecommons.org/ licenses/by/4.0/) DOI: http://dx.doi.org/10.22159/ajpcr.2021v14i9.42342. Journal homepage: https://innovareacademics.in/journals/index.php/ajpcr

\section{INTRODUCTION}

Laboratory analytical turnaround time (TAT) is a reliable indicator of laboratory effectiveness. Clinical laboratory plays a major part in aiding the health care providers to make accurate decisions, where it performs tests, which are requested by the health care providers on their patients' specimens and produce accurate and precise results [1]. These results must be available and accessible whenever they are needed by the healthcare providers [2].

It is very important for healthcare providers to obtain laboratory results as quickly as possible so as to confirm or refute the diagnosis of a medical condition or prescribe a medication in a timely manner $[3,4]$. This will improve the efficiency and effectiveness of the delivered health care services, which, in turn, leads to improved patient satisfaction. Conversely, patients' health condition may become worse in case the laboratory results are delayed [2].

Many quality indicators are continuously monitored, analyzed, and used to allocate resources and improve service. These quality indicators include the TATs necessary to report laboratory results to clinical staff. The total TAT (TTAT) for laboratory assays includes the entire interval from ordering of the test to the clinician's awareness of the result (i.e., "brain-to-brain"). It consists of the intervals from order placement to specimen collection, as well as the time necessary for transport to the laboratory, accessioning in the laboratory, centrifugation, aliquoting, additional pre-analytic steps if necessary, transport times within and between laboratories, analysis time, the time after completion of analysis until result verification, and the time it takes for the clinical team to be informed of the result [5].

For the laboratory, TAT is considered an indicator of its performance, which means the shorter the TAT the more efficient a laboratory is in producing reliable results in a timely manner $[2-4,6]$. TAT also helps in evaluating the laboratory quality. The present study was conducted to study the laboratory TAT to evaluate delay of TAT and to find out reasons for delay in TAT in diagnosing Coronavirus disease (COVID)-19.

\section{METHODS}

This is a cross-sectional, descriptive, and observational study based on the data obtained from the Department of Microbiology, Molecular Laboratory section, Central Laboratory, Trichy SRM Medical College Hospital, and Research Centre from August 2020 to March 2021 for the purpose of diagnosing COVID-19 only. All obtained data were closely analyzed to observe current TAT and factors affecting prolonged TAT. All the samples along with their test requisition form available at the Department of Microbiology in Central Laboratory were included in this study.

TTAT of an assay is defined as the time interval from test request to the clinician's awareness of the results. Laboratory TAT (LTAT), on the other hand, can be defined differently depending on test type (urgent vs. routine), analyze, and institution. However, it is generally defined by the time interval from the point of accessioning to the time the results are released. "Accessioning" in this context is defined as the reception of specimens at the laboratory either by scanning of barcoded samples as "received" or manually registering the specimen onto the laboratory information system (LIS), whereas "result time" is defined as the release of finalized validated results into the LIS [7].

Total laboratory testing process is divided into three phases, namely, pre-analytical, analytical, and post-analytical, and TAT depends on these three phases. The pre-analytical phase refers to the time period between requisition of the test to the sample being reached to the hands of professionals and prepared for analysis. The analytical phase is the period of measurement; this is the interval between the beginning of the measurement (actual testing) and the confirmation of the test results. The post-analytical period indicates the time from result verification or printing to the time when the physician actually observes the results [8-10]. 


\section{RESULTS}

The data related to the total samples of 4500 for the purpose of diagnosing COVID-19 were included in this study to determine the attained qualitative matrix TAT for the test performances.Out of them, 3126 were from outpatient departments (OPD) and inpatient departments (IPD); and others were from emergency and intensive care units (ICU). The average TAT was $3 \mathrm{~h}$, and $3 \mathrm{~h}$ and 30 min for emergency and ICU services and IPD and OPDs, respectively. The delay in TAT was observed among $19.7 \%$ samples and the detailed description of TAT and different departments were depicted in Table 1.

The reason for prolonged TAT in preanalytical phase is well analyzed thereby it was divided into two groups including payment and specimen related. The predominant reasons among payment-related are wrong payment $(1.8 \%)$ followed by payment missing $(1.7 \%)$. The specimen related issues are delayed specimen transportation (5\%), unlabelled (3.2\%), etc, (Table 2).

The analysis of the reason for prolonged TAT during analytical phase are test repetitions (40.7\%), reagent-related issues (6.6\%) and machine breakdown (8.8\%), and the detailed specific reasons with frequency were interpreted in Table 3. The frequency for prolonged TAT for postanalytical phase was also analyzed thereby reporting software $(27.4 \%)$ is the only and predominant factor observed (Table 4). By this study, it is clearly known that such delays between the reporting of result and training the laboratory staff should be remembered in order to improve intra-LTAT.

\section{DISCUSSION}

Clinical laboratory is a significant component in aiding health care providers in the diagnosis, management, and assessing outcome of disease of patients based on the tests requested by the health care providers on their patients' specimens [1]. These results must be

Table 1: Number of samples from different departments and their average TAT

\begin{tabular}{lll}
\hline Descriptions & $\begin{array}{l}\text { Emergency } \\
\text { services and ICU }\end{array}$ & $\begin{array}{l}\text { OP and } \\
\text { Inpatient } \\
\text { services }\end{array}$ \\
\hline Total number of samples & 1374 & 3126 \\
Prolonged TAT samples & $96(2.1 \%)$ & $794(17.6 \%)$ \\
Average TAT of total samples & $3 \mathrm{~h}$ & $3 \mathrm{~h}$ and $30 \mathrm{~min}$ \\
Average TAT of prolonged TAT & $3 \mathrm{~h}$ and $40 \mathrm{~min}$ & $4 \mathrm{~h}$ and $10 \mathrm{~min}$ \\
sample & & \\
\hline TAT: Turnaround time, ICU: Intensive care unit, OP: Outpatient
\end{tabular}

Table 2: Reason and their frequency for prolonged TAT-Preanalytical phase

\begin{tabular}{llll}
\hline Factors & Specific reason & Number & $\begin{array}{l}\text { Frequency } \\
\text { (\%) }\end{array}$ \\
\hline $\begin{array}{l}\text { Payment for } \\
\text { tests in the } \\
\text { cash unit (54) }\end{array}$ & $\begin{array}{l}\text { Payment Missing } \\
\text { (Incomplete payment) }\end{array}$ & 15 & 1.7 \\
& $\begin{array}{l}\text { Wrong payment (Not } \\
\text { according to tests } \\
\text { prescribed) }\end{array}$ & 18 & 1.8 \\
& $\begin{array}{l}\text { Wrong registration (Paid in } \\
\text { another patients account) }\end{array}$ & 10 & 1.4 \\
& $\begin{array}{l}\text { Excess payment (Mostly } \\
\text { double payment) }\end{array}$ & 11 & 1.5 \\
& $\begin{array}{l}\text { Unlabelled } \\
\text { Specimen }\end{array}$ & 29 & 3.2 \\
related (93) & $\begin{array}{l}\text { Delayed transport of } \\
\text { specimen }\end{array}$ & 46 & 5 \\
Total & 18 & 147 & 16.6 \\
\hline
\end{tabular}

available and accessible whenever they are needed by the healthcare providers [2]. The precision, accuracy and timeliness in releasing results to clinicians are vital to ensure that patients get the best care possible.

Clinicians consider TAT from the time the test is ordered to results reporting, whereas laboratory professionals usually use specimen receipt to report results as the TAT [11].

Delays in laboratory results reporting would cause a delay in the diagnosis and management of patients that leads to complications of the disease.A study showed that there was $43 \%$ treatment delay and $61 \%$ increased length of stay in the emergency department [12]. Moreover, a slow TAT can lead to increase in requests which results in duplication of the test [13]. This further increases the workload in the laboratory, and may again increase the cost burden of the health care [14]. Therefore, faster TAT is universally desirable for efficient and effective management of patients in addition to saving time and money.

Specific analysis for individual departments showed average TAT for emergency room (ER) and ICU departments and OPD and indoor departments as $3 \mathrm{~h}$ and $3 \mathrm{~h} 30$ min andaverage prolonged TAT in ER and ICU services to be $2.1 \%$; average prolonged TAT in inpatient and OP services to be $17.6 \%$. This is in concordance with the study that showed that only $2.03 \%$ of samples had prolonged TAT in ER and ICU services [15]. This variation in TAT was mainly due to the delayed entry of the time at which the report was generated. The laboratory technicians generally inform the ER and ICU department immediately via phone call and dispatch the report immediately.

In the present study, 147 samples $(16.6 \%)$ had delayed TAT in the pre-analytical phase. Delayed transport of specimens to the molecular laboratory contributes to $5 \%$ of delayed TAT. The time taken to

Table 3: Reason and their frequency for prolonged TAT-analytical phase

\begin{tabular}{|c|c|c|c|}
\hline Factors & Specific reason & Number & $\begin{array}{l}\text { Frequency } \\
\text { (\%) }\end{array}$ \\
\hline \multirow[t]{2}{*}{$\begin{array}{l}\text { Tests repetition } \\
(362)\end{array}$} & $\begin{array}{l}\text { Critical value } \\
\text { reconfirmation and } \\
\text { consultation }\end{array}$ & 325 & 36.5 \\
\hline & Insufficient & 37 & 4.15 \\
\hline \multirow[t]{2}{*}{$\begin{array}{l}\text { Reagents } \\
\text { related (59) }\end{array}$} & Out of stock/Not provided & 15 & 1.7 \\
\hline & Invalid CHIP & 44 & 4.9 \\
\hline \multirow{2}{*}{$\begin{array}{l}\text { Machine } \\
\text { breakdown } \\
(78)\end{array}$} & Random breakdown & 55 & 6.3 \\
\hline & $\begin{array}{l}\text { Preventive maintenance } \\
\text { schedule }\end{array}$ & 23 & 2.6 \\
\hline Total & & 499 & 56.1 \\
\hline
\end{tabular}

TAT: Turnaround time

Table 4: Reason and their frequency for prolonged TAT-Post-analytical phase

\begin{tabular}{llll}
\hline Factors & Specific Reason & Number & $\begin{array}{l}\text { Frequency } \\
\text { (\%) }\end{array}$ \\
\hline $\begin{array}{l}\text { Reporting } \\
\text { software (244) }\end{array}$ & $\begin{array}{l}\text { Breakdown reporting } \\
\text { system }\end{array}$ & 59 & 6.6 \\
& $\begin{array}{l}\text { Result entry errors } \\
\text { Delay in obtaining hard } \\
\text { copy of reports through } \\
\text { dispatch centre }\end{array}$ & 65 & 7.3 \\
Total & & 244 & 13.5 \\
\hline
\end{tabular}


transport the specimen from the phlebotomy area to the laboratory can be reduced with the help of a pneumatic system. It was found that the inclusion of a pneumatic tubing system led to a significant reduction of TAT [16]. The pneumatic system is a path breaking innovation that has revolutionized sample transport and many studies have proven the efficiency of this mechanism in reducing the inadvertent delays as a result of human courier.

In the present study, the analytical phase contributes to $56 \%$ of delayed TAT. This could be explained by the fact that reconfirmation of critical value is emphasized as the disease goes for notification to the Government authorities that is accentuates that most of the delays were due to analyzer error constituting $40 \%$ of the total specimens [15]. The analytical phase of TAT can be reduced by using fully automated machines with higher throughput, adoption of efficient quality control procedures, training of technical staff to handle urgent samples with priority, and prompt validation of reports once tests are completed [17].

The delay in TAT in post- post-analytical phase contributes to $27.4 \%$, of which obtaining the hard copy of report in the dispatch counter contributes to $13.5 \%$. The post-analytical phase can be reduced by adoption of a laboratory information system. The manual dispatch of reports to the respective wards should stop, rather, the clinicians and staff nurses should be able to see the report on the computer and take their print-outs. This will in turn reduce the TAT in the post-analytical phase.

\section{CONCLUSION}

Improving TAT is a continuous process and we need to have a wholesome approach for reducing the obstacles for optimum TAT. It is clear from our critical self-appraisal of our laboratory services that we have improvised the analytical phase by automation, elaborate documentation, and communication of critical values and recruitment of trained laboratory personnel. There is a scope of further improvement in our TAT by initiating administrative machinery for acquiring state of the art pneumatic tube delivery system and LIS. There is also a pertinent need to devise a transparent and effective communication system between the clinicians and laboratorians.

\section{REFERENCES}

1. Barth JH.Clinical quality indicators in laboratory medicine. Ann Clin Biochem 2012;49:9-16.
2. Chien TI, Lu J, Kao JT, Cheng YC, Lee YF. Evaluation and improvement strategy of analytical turnaround time in the stat laboratory.J Formos Med Assoc 2007;106:558-64.

3. Dey B, Bharti JN, Chakraborty M. Laboratory turnaround time. Int J Health Sci Res 2013;3:82-4.

4. Goswami B, Singh B, Chawla R, Gupta VK, Mallika V. Turn around time (TAT) as a benchmark of laboratory performance. Ind J Clin Biochem 2010;25:376-9.

5. Kilgore ML, Steindel SJ, Smith JA. Evaluating stat options in an academic health centre: Therapeutic turnaround time and staff satisfaction. Clin Chem 1998;44:1597-603.

6. Elhoseeny T, Mohammad E. Quality of the clinical laboratory department in a specialized hospital in Alexandria, Egypt. East Mediter Health J 2013;19:81-7.

7. Sivaneson S, Ramaloo G, Martin G, Giddy M, George S, Rahman TA. Improving laboratory turnaround time in a high throughput medical laboratory.J Clin Chem Lab Med 2019;2:127-31.

8. Steindel SJ, Jones BA. Routine outpatient laboratory test turnaround times and practice patterns. Arch Pathol Lab Med 2002;126:11-8.

9. Chung HJ, Lee W, Chun S, Park HI, Min WK. Analysis of turnaround time by subdividing three phases for outpatient chemistry specimens. Ann Clin Lab Sci 2009;39:144-9.

10. Valenstein P. Laboratory turnaround time. Am J Clin Pathol 1996;105:676-88.

11. Howanitz JH, Howanitz PJ. Timeliness as a quality attribute and strategy. Am J Clin Pathol 2001;116:311-5.

12. Holland LL, Smith LL, Blick KE. Reducing laboratory turnaround time outliers can reduce emergency department patient length of stay. Am J Clin Pathol 2005;124:672-4.

13. Ialongo C, Porzio O, Giambini I, Bernardini S. Total automation for the core laboratory: improving the turnaround time helps to reduce the volume of ordered STAT tests.J Lab Autom 2016;21:451-8.

14. Imoh LC, Mutale M, Parker CT, Erasmus RT, Zemlin AE. Laboratorybased clinical audit as a tool for continual improvement: An example from CSF chemistry turnaround time audit in a South-African teaching hospital. Biochem Med 2016;26:194-201.

15. Bilwani F, Siddiqui I, Vaqar S. Determination of delay in turnaround time (TAT) of stat tests and its causes: An AKUH experience.J Pak Med Assoc 2003;53:65-7.

16. Fleisher M, Schwartz MK. Automated approaches to rapid-response testing.A comparative evaluation of point-of-care and centralized laboratory testing. Am J Clin Pathol 1995;104:18-25.

17. Bhagyashree KB. Monitoring of Turnaround time (TAT) in biochemistry laboratory of a tertiary care hospital in Karwar. Int $\mathrm{J}$ Biotechnol Biochem 2017;13:167-73. 